\title{
Gamma/Delta T Cell Lymphoma
}

\author{
Akihiko Taguchi, Mutsuko MiYaZAKI, Shizu SAKURAgI, Kenji SHINOHARA, \\ Toshiaki KAMEI* and Yusuke INOUE**
}

\begin{abstract}
A 54-year-old woman complained of fever and hepatosplenomegaly. The pathological findings of a liver biopsy specimen revealed the infiltration of lymphocytes in the sinusoids and that of the laparoscopically resected spleen revealed the infiltration of lymphocytes in the red pulp, which was positive for CD3, CD43, CD45RO and T-cell intracellular antigen-1 (TIA-1) and was negative for $\beta F 1$, while the white pulp was spared. Genetic analysis of the spleen cells revealed the rearrangement of $T$-cell receptor (TCR) C $\beta 1$, J $\delta 1$ and J $\gamma$. Epstein-Barr virus (EBV) genomic DNA was detected in the spleen cells. Atypical lymphocytes appeared in the peripheral blood and bone marrow, chromosomal analysis revealed del (13) (q12 q14), trisomy 8 and breakage of RB gene. Elevated level of serum vascular endothelial growth factor (VEGF) was observed. Hepatosplenic $\gamma \delta$ T cell lymphoma (GDTL) was diagnosed. The patient was treated with chemotherapy by cyclophosphamide, hydroxydoxorubicin, vincristine and prednisolone (CHOP), however, it was ineffective, and the patient died of hemorrhage from the lymphoma involvement of the intestine 5 months after the onset of disease.
\end{abstract}

(Internal Medicine 43: 120-125, 2004)

Key words: peripheral T-cell lymphoma, gamma-delta $\mathrm{T}$ cell, hepato-splenomegaly

\section{Introduction}

The T-cell receptor (TCR) consists of either an $\alpha \beta$ or $\gamma \delta$ heterodimer expressed in association with the CD3 complex of proteins on the cell surface $(1,2)$. The majority of mature T lymphocytes express the $\alpha \beta$ TCR; however, a small group of normal T cells express the $\gamma \delta$ TCR.
Peripheral T-cell lymphomas (PTCL) are clinically and morphologically heterogeneous tumors of post-thymic, mature lymphoid malignancies, accounting for approximately $10-15 \%$ of non-Hodgkin's lymphoma. They express TCR of the $\alpha \beta$ type in the vast majority of cases. A few rare cases of PTCL bearing $\gamma \delta$ TCR, $\gamma \delta$ T-cell lymphoma (GDTL), have been reported, with limited involvement of particular anatomical sites initially or mainly, such as in hepatosplenic, cutaneous, intestinal and nasopharynx $(3,4)$. The disease is still rare and there have been only about 100 reported cases in the world (3-5), and less than 10 cases in Japan $(6,7)$. Recently, there were reports of $\alpha \beta$ T-cell lymphoma which have similar clinical manifestations as GDTL, and the existence of each distinct clinico-pathological entity or common pathogenesis is discussed $(8,9)$. Here we present a case of GDTL in oredr to accumulate such cases and clarify the distinct clinicopatholpogical entity of GDTL.

For editorial comment, see $\mathrm{p} 83$.

\section{Materials and Methods}

Immunohistochemical studies of the biopsied liver and operatively resected spleen specimens were performed by immunoalkaline phosphatase method using monoclonal antibodies for CD3, CD43, UCHL1 (CD45RO), T-cell intracellular antigen (TIA-1) and $\beta \mathrm{F} 1$ (constant region of TCR $\beta$ ).

DNA extracted from spleen and bone marrow cells was extracted using standard techniques and analyzed for TCR rearrangement for $\mathrm{C} \beta 1, \mathrm{~J} \delta 1$ and $\mathrm{J} \gamma$ by Southern blot analysis using specific probes. Genomic Epstein-Barr virus (EBV) in DNA extracted from spleen cells was detected by Southern blot method using a specific probe. Interphase fluorescence in situ hybridization (FISH) for RB gene in bone marrow cells was performed using an RB1 probe.

From the Division of Hematology, Department of Medicine, *Department of Pathology, Yamaguchi Prefecture Central Hospital, Hofu and **Department of Medicine, Yamato Municipal Hospital, Yamato

Received for publication May 12, 2003; Accepted for publication September 20, 2003

Reprint requests should be addressed to Dr. Kenji Shinohara, the Division of Hematology, Department of Medicine, Yamaguchi Prefecture Central Hospital, Hofu 747-8511 


\section{Case Report}

The 54-year-old woman complained of fever, general dullness, anorexia and edema of the bilateral legs in December 2001. She was referred to our hospital with hepato-splenomegaly and an elevated level of soluble IL-2 receptor in January 2002. Her past history did not reveal any specific disease. Physical findings on admission revealed a palpable liver of $2 \mathrm{~cm}$, spleen of $4 \mathrm{~cm}$, edematous legs, although superficial lymph nodes were not palpable. Nasal lesion was absent. The symptoms of autoimmune diseases were not observed. Computed tomography (CT) and magnetic resonance imaging (MRI) revealed hepato-splenomegaly. Laboratory data on admission are shown in Table 1. Elevated levels of soluble IL-2 receptor and vascular endothelial growth factor (VEGF) were observed. Atypical lymphocytes appeared in the peripheral blood and bone marrow in $10 \%$ of leukocytes since February (Fig. 1). Liver biopsy under laparoscopy was performed, and the specimen revealed infiltration in the sinusoids and inter lobular connective tissue by lymphoid cells (Fig. 2), which were positive for CD43, CD45RO and TIA-1. Subsequently, laparoscopic splenectomy was performed. The spleen weighed $640 \mathrm{~g}$ and revealed diffuse infiltration in the red pulp and sinusoidal

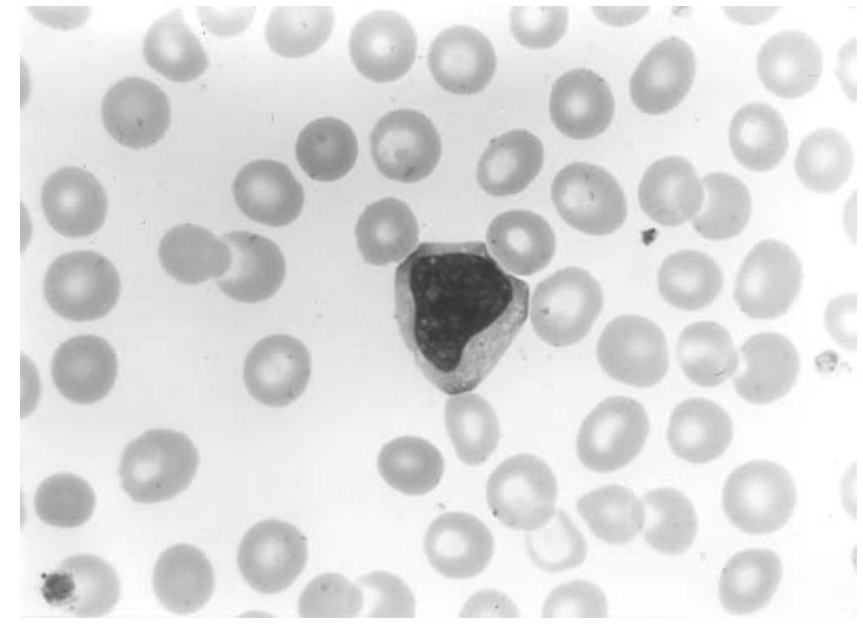

Figure 1. Atypical large lymphocytes with irregularly shaped nuclei and pale-appearing cytoplasm without azurophilic granules were observed in the peripheral blood.

Table 1. Laboratory Data on Admission

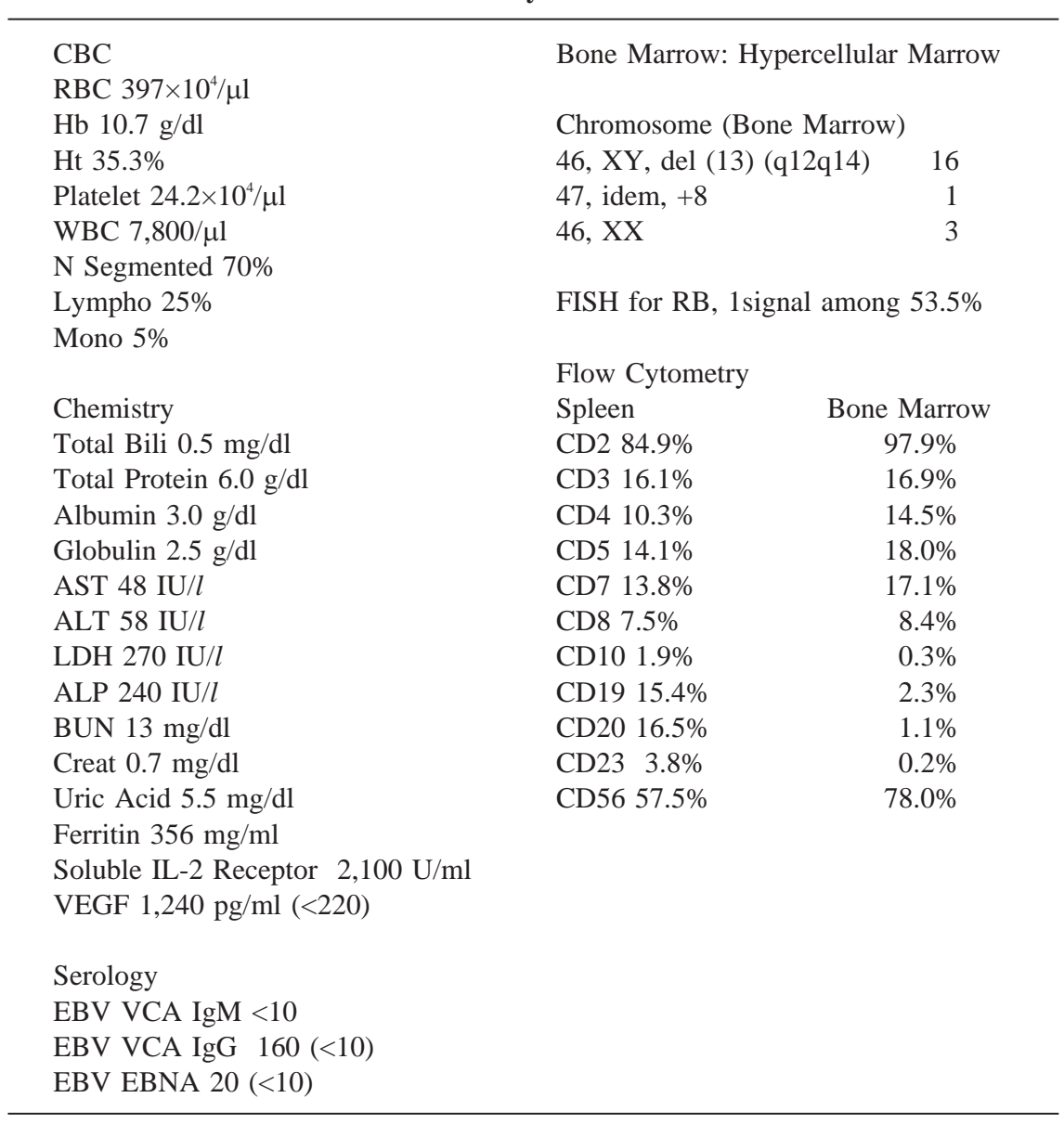




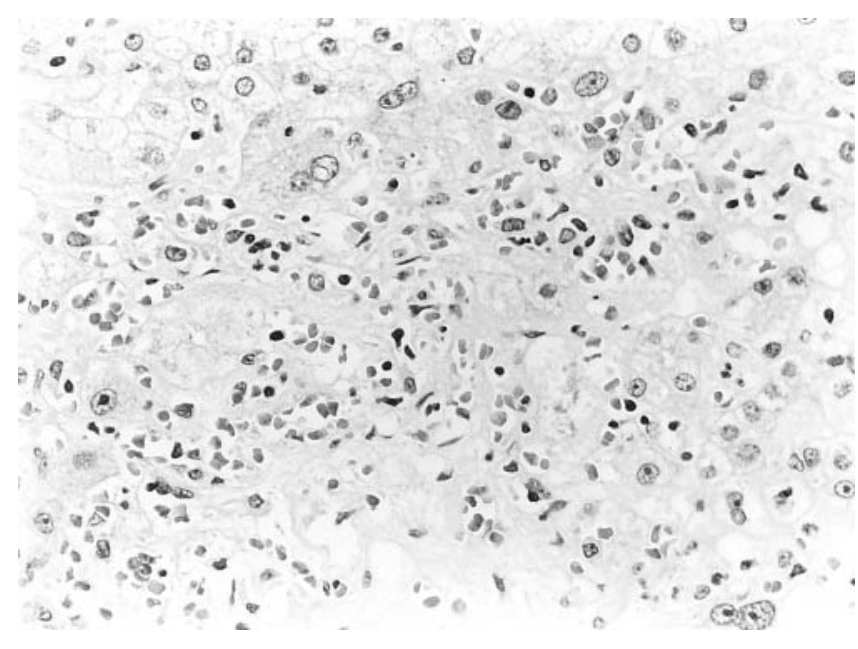

Figure 2. Pathological finding of laparoscopically biopsied liver, HE staining. Infiltration of small to medium sized lymphocytes in the sinusoids and interlobular connective tissue was observed.

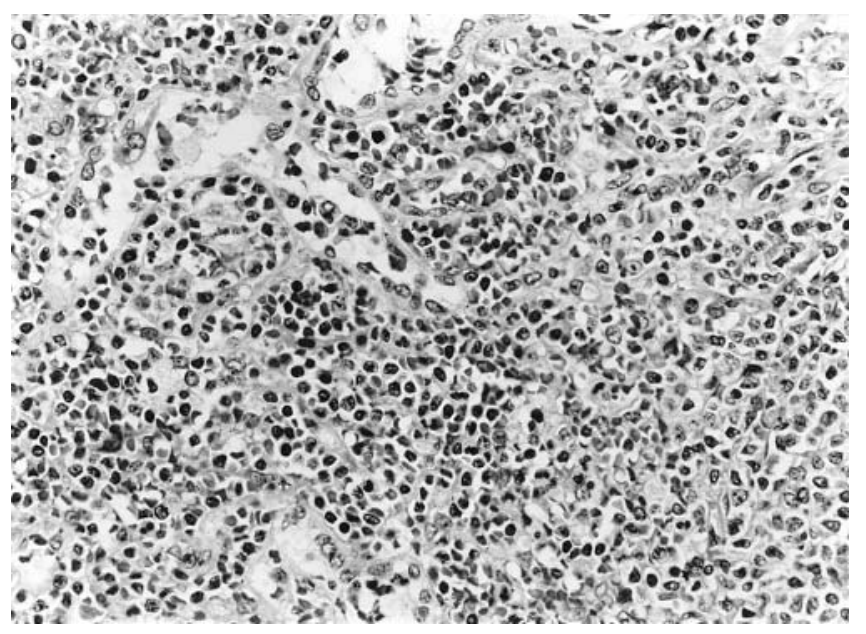

A

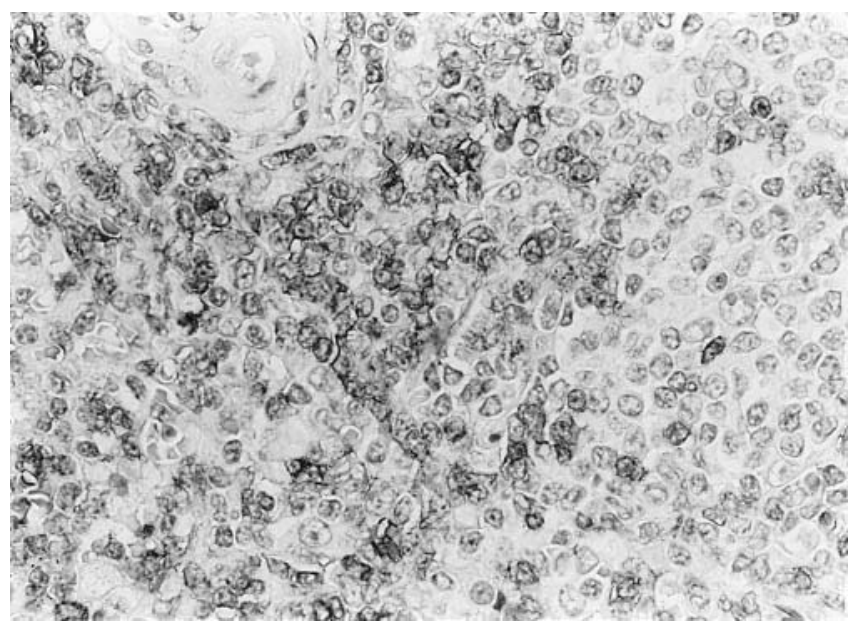

area by small to medium sized lymphocytes (Fig. 3A), which were positive by immunohistochemistry for CD3 (Fig. not shown), CD43 (Fig. 3B), CD45RO (Fig. 3C) and TIA-1 (Fig. not shown), was negative for $\beta F 1$ (Fig. not shown), while the white pulp was spared. Flow cytometry analysis of bone marrow and spleen cells were highly positive for CD2 and CD56 and were also positive for CD3 although low (Table 1). Chromosomal analysis revealed del (13) (q12q14) in 16 and +8 in 1 among 20 metaphases in the bone marrow cells, while abnormality was not observed in the spleen cells. Fluorescence in situ hybridization (FISH) for RB gene revealed 1 signal among $53.5 \%$ and 2 signals among $46.7 \%$ of cells examined (normal control, 2 signals in $100 \%$ of cells). Rearrangement of T-cell receptor (TCR) C $\beta 1, \mathrm{~J} \delta 1$ and $\mathrm{J} \gamma$ genes were observed in the spleen cells (Fig. 4A-C). Rearrangement of TCR J $\delta 1$ was observed, while that of TCR $\mathrm{C} \beta 1$ and $\mathrm{J} \gamma$ were not observed in the bone marrow cells. Antibodies for EBV viral capsid antigen (VCA) IgG and nuclear antigen (EBNA) were elevated. Genomic Epstein Barr virus (EBV) was detected in the spleen cells. Pathological,

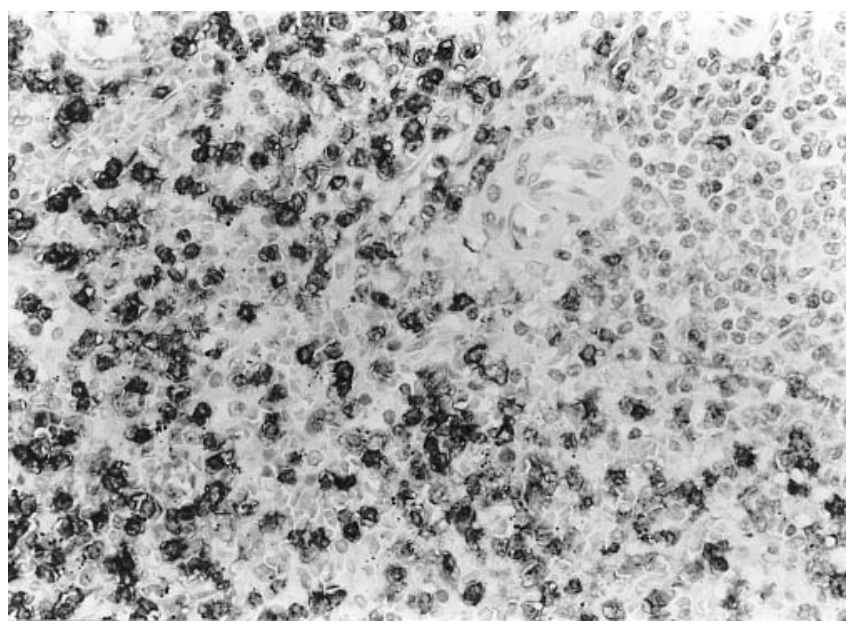

B

Figure 3. Pathological finding of laparoscopically resected spleen. A. Infiltration by small to medium sized lymphocytes in the red pulp was observed while the white pulp was spared by HE staining, and those lymphocytes were , B. CD43 positive and, C. CD45RO positive. 
Hepato-splenic $\gamma \delta$ T-cell Lymphoma

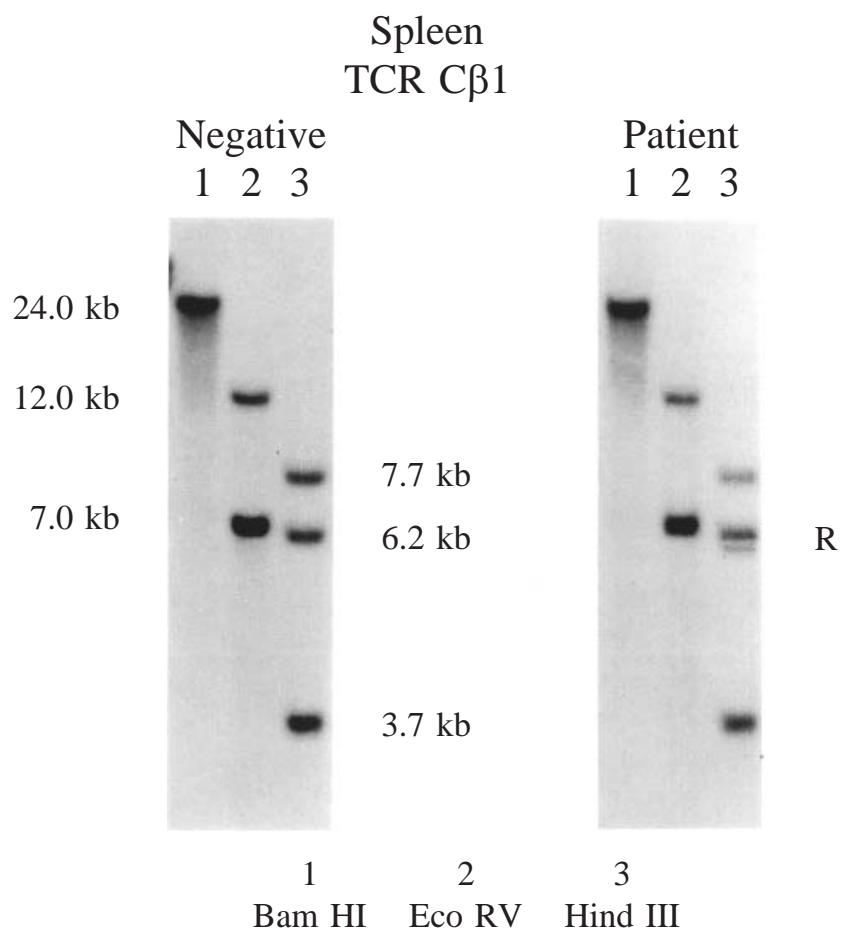

A

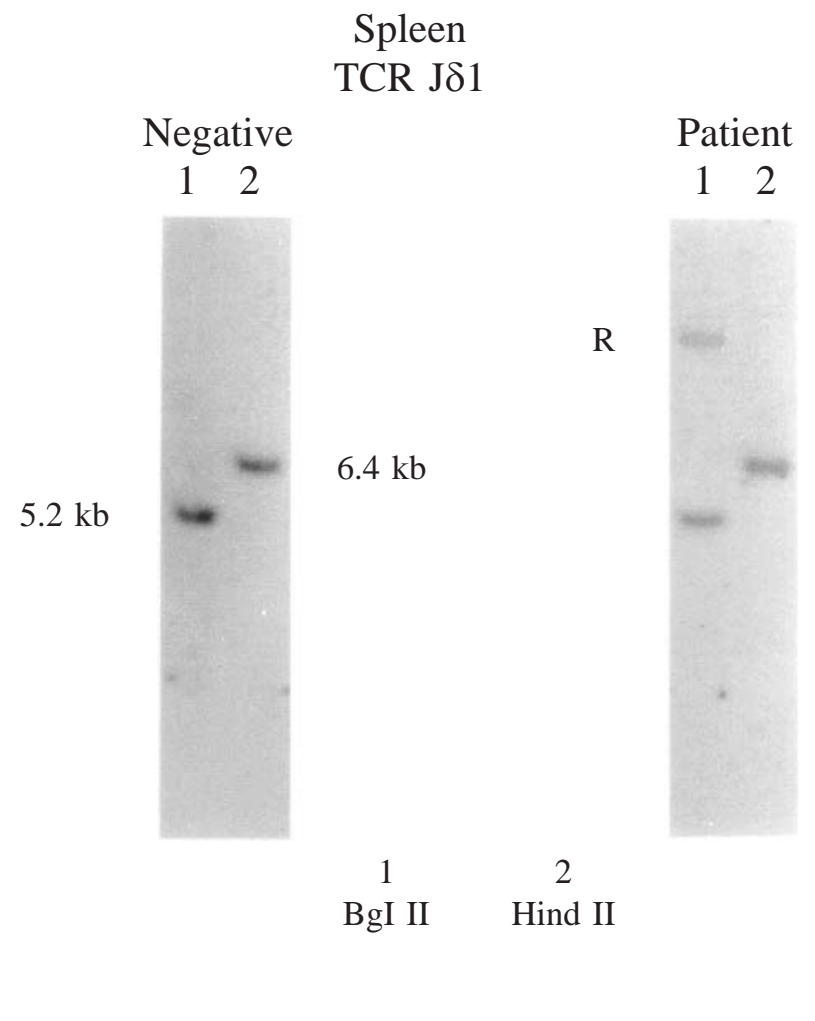

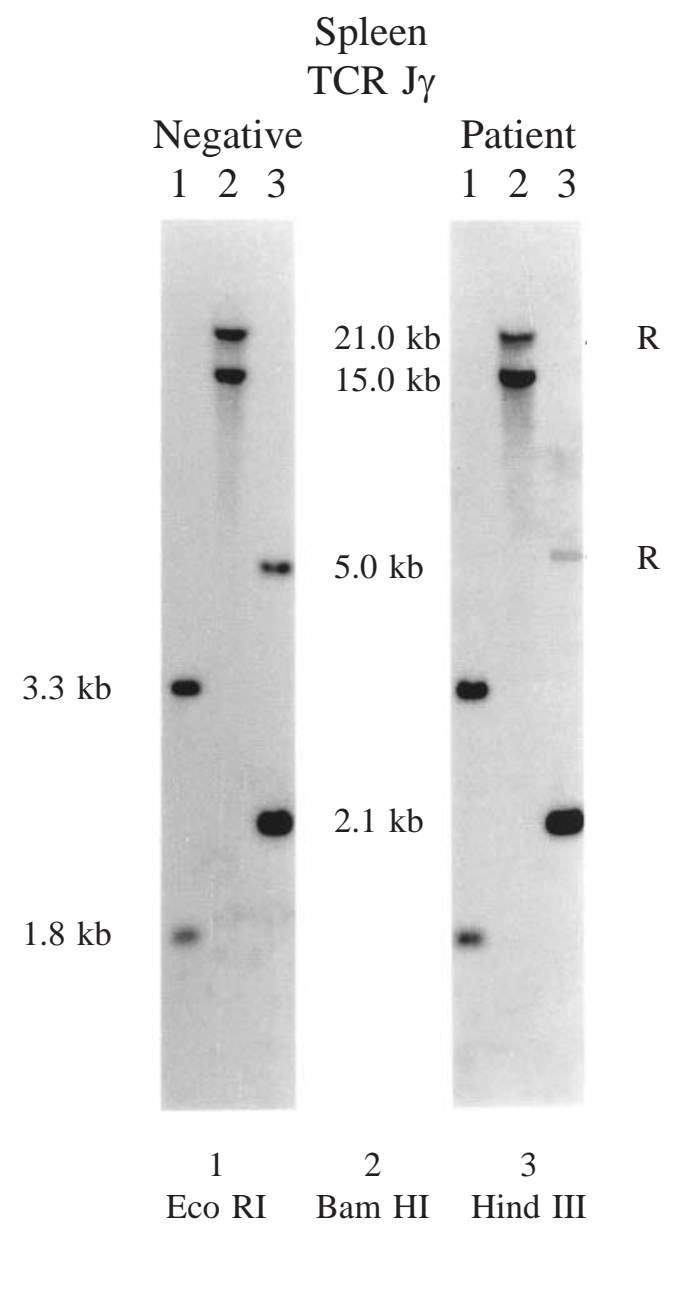

Figure 4. Rearrangement of TCR genes of the spleen cells. R: denotes the rearranged bands. A. Cß1, B. J反1, C. J $\gamma$. 
immunohistochemical and genetic studies diagnosed hepatosplenic $\gamma \delta \mathrm{T}$ cell lymphoma (GDTL). Chemotherapy with cyclophosphamide, hydroxydoxorubicin, vincristine (Oncovin) and prednisolone (CHOP) was started on the beginning of April. However, the clinical picture and laboratory data did not improve. The second course of CHOP was started at the end of April. Melena appeared in mid-May and endoscopic examination of the colon revealed hemorrhagic ulcerative lesions around the cecum, a biopsy of which showed the infiltration of lymphoma cell in the propria of the intestine. Massive intestinal bleeding continued, red cells transfusion was not effective and the patient died at the end of May, 5 months after the onset of the disease.

\section{Autopsy finding}

Infiltration of lymphoma cells was observed in the liver, pancreas, stomach, duodenum, small intestine, large intestine, kidney, intraabdominal lymph nodes and bone marrow.

\section{Discussion}

Human $\gamma \delta$ T cells exhibit preferential homing to the sinusoidal areas, liver, red pulp of the spleen, bone marrow and into the epithelial layer of the intestine, whereas $\alpha \beta$ T cells migrate preferentially to the splenic periarterial sheaths and intestinal lamina propria, and this specialized anatomical distribution pattern suggests the selective expression of a homing molecule and important physiologic function of the $\gamma \delta \mathrm{T}$ cells $(3,4)$. According to these properties of $\gamma \delta \mathrm{T}$ cells, several types of GDTL involving initially or mainly particular organs are reported; hepatosplenic 50 cases, cutaneous 25 cases, intestinal 5 cases, nasal 5 cases, nodal 5 cases and $1-$ 2 cases in the stomach, lung, larynx and thyroid (7). In the present case, GDTL initially developed in the liver and spleen, later involved the intestine, and was finally widespread. There may be more cases of GDTL and the disease may not be so rare since there were 6 cases among 115 cases of PTCL in one institution $(6,7)$. Each case of GDTL should be reported in detail to clarify the clinicopathological entity.

Frequent chromosomal abnormalities observed in this disorder are isochromosome $7 \mathrm{q}$, and it is often associated with trisomy 8; the combination of both seems to be unique in $\operatorname{GDTL}(5,10,11)$. It was considered that isochromosome $7 \mathrm{q}$ may represent the primary chromosomal alteration and trisomy 8 may be the secondary change, while trisomy 8 without isochromosome 7 had not been reported (5). However, GDTL with different karyotypes has been reported, and in particular two cases with -13 were observed (5). The present patient had $\operatorname{del}(13)(\mathrm{q} 12 \mathrm{q} 14)$ in 16 and trisomy 8 in 1 of 20 metaphases in the bone marrow cells, and the breakage of RB gene at chromosome 13 was observed by interphase FISH, therefore the significance of the $\mathrm{RB}$ gene mutation was suggested for the pathogenesis of GDTL. However, chromosomal abnormality was not observed in the spleen cells, and the reason is unknown.

In the present patient, rearrangement of TCR $\beta, \gamma$ and $\delta$ genes was observed in the spleen cells and that of $\delta$ gene was observed in the bone marrow cells. CD3 was positive although low in the bone marrow and spleen cells by flow cytometry analysis in our patient, however the other pan $\mathrm{T}$ antigen, CD2, was highly positive. In addition, CD3 was positive in the lymphoma cells of spleen by immunohistological staining. Rearrangement of the TCR $\delta$ gene is observed in human T-cell leukemias, and is the first to rearrange among TCR genes followed by the rearrangement of $\gamma$ and subsequently $\alpha$ and $\beta$ genes in T cell ontogeny (12). Rearrangements of genes of TCR $\beta$ were observed in $10 / 18$, TCR $\gamma$ in 15/15 and TCR $\delta$ in 14/14 of GDTL cases and demonstrated clonality of the malignant cells (5). Rearrangement of TCR $\beta$ gene was also observed in $1 / 3$ (6), and $2 / 6$ of cases with GDTL (13). The presence of the rearrangement of TCR genes does not necessarily indicate the presence of those products. Immunophenotypic examination of lymphoma cells using monoclonal antibody $\beta \mathrm{F} 1$ was negative, while that using TCR $\delta 1$ was not performed and the presence of the product of TCR $\gamma \delta$ was not confirmed in the present patient. However, typical cases of GDTL were $\mathrm{CD} 3+, \beta \mathrm{F} 1-$ and TCR $\delta 1+(6,13)$. These results indicated the nonproductive TCR- $\beta$ gene rearrangement $(5,6,13)$. There are three types of PTCL; $\alpha \beta, \gamma \delta$ and silent TCR type $(6,13)$. The result may support the common pathogenesis of GDTL and $\alpha \beta$ T-cell lymphoma since the latter shares the clinical, histopathologic and cytogenetic features with $\operatorname{GDTL}(8,9)$. Further study is necessary to define the distinct clinicopathologcal features of each disease $(8,9)$.

Usually $\gamma \delta$ T cells are CD2+CD3+CD4-CD5-CD7+CD8$(3,4,6)$ and the marker for natural killer (NK) cells, CD16/CD56, is frequently positive $(4,6,14)$ representing the NK cell and NK-like T cell lymphoma (15). This fact necessiates the differential diagnosis of GDTL from NK lymphoma (15). The $\gamma \delta \mathrm{T}$ cells share many functional and phenotypic similarities with NK cells and NK-like T cells, and therefore, clinical overlap among these malignancies is not surprising. The bone marrow and spleen cells in the present patient were highly positive for CD2+CD56+ by flow cytometry analysis. Azurophilic granules were not observed in the atypical lymphocytes in the peripheral blood and bone marrow. These results in our patient favor the diagnosis of GDTL.

NK cell lymphomas usually present with localized extranodal disease, a high incidence of nasal involvement, and nearly constant positivity for EVB (15). Early studies in GDTL did not demonstrate the relation to Epstein-Barr virus (EBV) infection $(7,15)$, however GDTL had been reported recently in an immunocompromised host (16) and in posttransplant lymphoproliferative disorder (PTLD) (17) in relation to EBV infection demonstrating EBV nuclear antigen (EBNA)-2, latent membrane protein (LMP)-1 and EBVencoded small RNA (EBER) transcripts proved by in situ hybridization. In the present patient, EBV genomic DNA was detected in the spleen cells by Southern blot analysis suggesting the relation to EBV infection for the pathogenesis of 
Hepato-splenic $\gamma \delta$ T-cell Lymphoma

GDTL.

Edema of the legs was observed in the present patient. It is not known whether this symptom is particular in our patient, since it has not yet been described as a clinical manifestation of GDTL. The elevated level of VEGF produced by lymphoma cells may have contributed to the pathogenesis of the leg edema in this case.

The prognosis of this disease is poor (3-7) as in the present patient. Treatment included splenectomy, multiagent chemotherapy including CHOP, third generation regimens, purine analogues and autologous and allogeneic bone marrow or peripheral blood stem cell transplantation $(5,7,18$, 19). Splenectomy was performed in 16 cases among 46 patients reported and ameliorated the disease substantially but ultimately accelerated the aggressive course of the disease (7). The standard chemotherapy of CHOP was performed in almost all of the cases, however complete remission was obtained in only 5 of 46 cases $(5,7)$. Only 5 cases survived including 2 patients who received bone marrow transplantation, and all of the remaining patients died and 21 patients died within a year (7). These results indicate that the curative treatment for GDTL is not so simple. Transplanation in a short period of remission after chemotherapy may be a choice of treatment $(5,7)$. As GDTL is still rare and its pathogenesis is not well understood; more insight in the biology of the disease may contribute to the development of a more appropriate therapeutic modality.

\section{References}

1) de Villartay JP, Pullman AB, Andrade R, et al. $\gamma / \delta$ lineage relationship within a consecutive series of human precursor T-cell neoplasms. Blood 74: 2508-2518, 1989.

2) Picker LJ, Brenner MB, Michie S, Warnke RA. Expression of T-cell receptor delta chains in benign and malignant $\mathrm{T}$ lineage lymphoproliferations. Am J Pathol 132: 401-405, 1988.

3) Farcet JP, Gaulard P, Marolleau JP, et al. Hepatosplenic T-cell lymphoma: sinusal/sinusoidal localization of malignant cells expressing Tcell receptor $\gamma \delta$. Blood 75: 2213-2219, 1990.

4) Cooke CB, Krenacs L, Stetler-Stevenson M, et al. Hepatosplenic T-cell lymphoma: a distinct clinicopathologic entity of cytotoxic $\gamma \delta$ T-cell origin. Blood 88: 4265-4274, 1996.

5) Weidmann E. Hepatosplenic $T$ cell lymphoma. A review on 45 cases since the first report describing the disease as a distinct lymphoma entity in 1990. Leukemia 14: 991-997, 2000.

6) Yamaguchi M, Ohno T, Nakamine $\mathrm{H}$, et al. $\gamma \delta$ T-cell lymphoma: a clinicopathologic study of 6 cases including extrahepatosplenic type. Int J Hematol 69: 186-195, 1999.

7) Yamaguchi M. Gamma/delta T-cell lymphoma. Ketsueki · Shuyouka 42: 54-60, 2001 (In Japanese).

8) Lai R, Larratt LM, Etches W, et al. Hepatosplenic T-cell lymphoma of $\alpha \beta$ lineage in a 16-year-old boy presenting with hemolytic anemia and thrombocytopenia. Am J Surg Pathol 24: 459-463, 2000.

9) Suarez F, Wlodarska I, Rigal-Huguet F, et al. Hepatosplenic $\alpha \beta$ T-cell lymphoma. An unusual case with clinical, histologic, and cytogenetic features of $\gamma \delta$ hepatosplenic T-cell lymphoma. Am J Surg Pathol 24: 1027-1032, 2000.

10) Wang C-C, Tien H-F, Lin M-T, et al. Consistent presence of isochromosome $7 \mathrm{q}$ in hepatosplenic $\mathrm{T} \gamma / \delta$ lymphoma: a new cytogenetic-clinicopathologic entity. Genes Chromosomes Cancer 12: 161164, 1995.

11) Jonveaux $P$, Daniel MT, Martel $V$, Maarek $O$, Berger $R$. Isochromosome $7 \mathrm{q}$ and trisomy 8 are consistent primary, non-random chromosomal abnormalities associated with hepatosplenic T $\gamma / \delta$ lymphoma. Leukemia 10: 1453-1455, 1996.

12) Foroni L, Laffan M, Boehm T, Rabbitts TH, Catovsky D, Luzzatto L. Rearrangement of the T-cell receptor $\delta$ genes in human T-cell leukemias. Blood 73: 559-565, 1989.

13) Gaulard P, Bourquelot P, Kanavaros P, et al. Expression of the alpha/beta and gamma/delta T-cell receptors in 57 cases of peripheral T-cell lymphomas. Identification of a subset of $\gamma \delta$ T-cell lymphomas. Am J Pathol 137: 617-628, 1990.

14) Jaffe ES. Classification of natural killer (NK) cell and NK-like T-cell malignancies. Blood 87: 1207-1210, 1996 (editorial: comment).

15) Harris NL, Jaffe ES, Stein H, et al. A revised European-American classification of lymphoid neoplasms: a proposal from the international lymphoma study group. Blood 84: 1361-1392, 1994 (see comments).

16) Khan WA, Yu L, Eisenbrey AB, et al. Hepatosplenic gamma/delta Tcell lymphoma in immunocompromised patients. Report of two cases and review of literature. Am J Clin Pathol 116: 41-50, 2001.

17) Kraus MD, Crawford DF, Kaleem Z, Shenoy S, MacArthur CA, Longtine JA. T $\gamma / \delta$ hepatosplenic lymphoma in a heart transplant patient after an Epstein-Barr virus positive lymphoproliferative disorder. A case report. Cancer 82: 983-992, 1998.

18) Aldinucci $D$, Poletto $D$, Zagonel V, et al. In vitro and in vivo effects of $2^{\prime}$-deoxycoformycin (Pentostatin) on tumor cells from human $\gamma \delta^{+} \mathrm{T}$ cell malignancies. Br J Haematol 110: 188-196, 2000.

19) Ooi J, Iseki T, Adachi D, et al. Successful allogeneic bone marrow transplantation for hepatosplenic gammadelta $\mathrm{T}$ cell lymphoma. Haematologica 86: E25, 2001. 